\title{
Learning Japanese Script through Storytelling and Multimedia
}

\author{
Marija Bilić \\ University of Regensburg Germany \\ marija.bilic@stud.uni-regensburg.de \\ Tomislava Lauc \\ Faculty of Humanities and Social Sciences, University of Zagreb, Croatia \\ tlauc@ffzg.hr \\ Sanja Kišiček \\ Faculty of Humanities and Social Sciences, University of Zagreb, Croatia \\ smatic@ffzg.hr
}

\begin{abstract}
Summary
This paper offers a rationale for storytelling and multimedia in the context of learning the Japanese script Hiragana. There is a growing interest in the field of computer-assisted language learning (CALL) of Japanese and the use of multimedia to achieve learning goals. The complexity of the Japanese writing system raises a lot of questions on how to accelerate and improve the process of learning Japanese scripts. In the domain of CALL and multimedia, this paper considers the methodological approach to language learning and presents a design of a multimedia tutorial for learning Japanese script Hiragana. The paper synthesizes multimedia and storytelling with its implications to learning and instructional design to inform creation of such a framework.
\end{abstract}

Key words: multimedia, storytelling, CALL, learning Japanese

\section{Introduction}

The development of computers and information and communication technologies (ICT) has impacted how approaches to teaching and learning have changed through history. Computers have been used in language learning since the 1960s (Seljan et al. 2004) and from that time to the present we are talking about computer-assisted language learning (CALL). With multimedia, opportunities to improve language learning and teaching have significantly increased (Kišiček et al., 2010). However, multimedia alone is not enough to achieve the desired learning outcomes. Multimedia needs to be integrated in the learning environment through an instructional design that purposefully leads the student to desired learning outcomes. Thus, the question that is asked in the context of language didactics is how to conceptualize foreign language teaching to achieve the learning goals more effectively in the context of multimedia didactics (Matasić, Dumić, 2012).

CALL is an interdisciplinary field that integrates applied linguistics and computing. According to Beatty (2003), CALL is "any process in which a student uses a computer and, as a result, improves his or her language." Specifically, CALL encompasses several issues such as material design, technologies, pedagogical theories, and teaching methods. Beatty (2003) states that CALL is still a highly unstructured discipline as it is constantly evolving with breakthroughs in pedagogy and with advances in hardware and software development. The development of CALL is also affected by the increasing level of computer literacy of teachers and students using CALL applications. Since the 1990s, a large number of CALL systems has been developed. During this period, there was an increasing emphasis on multimedia CALL, that is, CALL systems in a multimedia environment.

Simultaneous presentation of different multimedia elements creates an authentic environment for language learning including all the necessary aspects for learning a language: reading, writing, listening and speaking (Lauc et al., 2007). This paper describes the elements of instructional design such as multimedia and storytelling, on the example of the Japanese script Hiragana. 


\section{Multimedia in learning Japanese}

In terms of how to learn and teach Hiragana script, tasks are traditionally based on reading and writing exercises, and various mnemonics are often used to improve memorizing of particular characters. The same principle applies to computer-aided language learning tools.

The opportunities offered by the multimedia environment have changed the concepts of learning and teaching. The new scientific discipline - multimedia didactics - is taking a central stage. Multimedia didactics deals with the learning goals and the design of educational content, as well as with the evaluating the effectiveness of multimedia projects and applications (Matasić, Dumić, 2012). The basis of this is, of course, the development of learning and teaching strategies, didactic and media design, and communication via the Internet. One of the most complex tasks in this context is to prepare a multimedia learning project. This job is extremely complex because it involves a large number of professionals in various fields. Professors, teachers, and lecturers are responsible for the material itself; instructional designers are responsible for presenting the material adapted to the new media, and the implementation itself is done by development experts such as graphic designers and developers. Also, multimedia language learning project is specific to language that is being learned.

The use of multimedia in language learning will not be the same for every language. In the example of computer-aided and multimedia learning in Japanese, it is evident that there is a large number of programs and applications that aim to teach Japanese script. The Japanese writing system consists of three letters, a hiragana, a katakana (kana) and a kanji (Yamaguchi, 2007). Numerous studies have been carried out to determine how and to what extent CALL and multimedia applications help to learn Japanese letters, and they also list various advantages and disadvantages of existing applications.

Hiragana and katakana mnemonics are often used by native speakers in Japanese language teaching and learning (Gilhooly, 2003). The usefulness of such a method of learning and remembering is recognized more widely, as indicated by the existence of material for English speakers. Since mnemonics for learning Japanese script are mainly available only for major world languages, as mentioned by Librenjak (2018) in Teaching Kana to Croatian Students, mnemonics were created for Croatian students of Japanese. The main goal was to design an illustration that connects the kana letter with the Croatian word beginning with the same syllable, for example, the hiragana letter あ / a / is shown as an aquarium in which a fish swims. These mnemonics were implemented in an Anki application that is based on a time-lapse learning method - how often a student answers the wrong question so often that question is repeated. Anki exists as a computer and mobile version which allows the student not to be attached to the classroom or computer, but to learn and repeat anytime, anywhere. Besides, each replay card contains multimedia, mostly in text and image (with Anki supporting both audio and video, but these elements are not included in the canoe mnemonics listed). It should be noted that Librenjak (2018) intended the application as supplementary material for learning scripture, in combination with teaching and traditional teaching methods (such as writing and reading exercises). By itself, the application cannot transfer all the skills needed to master the letter completely.

There is a great deal of research that analyses letter learning apps. Thus Moroz (2013) compares the advantages and disadvantages of two kanji learning applications. One of them (KanjiBox) is based on repetition cards (similar to Anki in the previous example) but also includes various quizzes and other types of exercise tasks. It also offers the option of ranking according to student performance and records various statistics. Another application (Kotoba!) is like a dictionary whose entries include kanji, reading it, translating it into English, and example sentences.

Mayer (2017) brings research/based principles for how to design computer-based multimedia instructional materials to promote learning. Arima (2009) considers aspects of instructional design when designing CALL and multimedia learning website and states that the high-quality instructional design includes interface consistency, simplicity, ease of navigation, and an adequate combination of colors and fonts. The site navigation needs to be designed in a visible and easily accessible location without interfering with learning. Websites can offer different multimedia elements such as videos for learning the correct way to write characters and audio files with authentic Japanese pronunciation. 


\section{Storytelling}

Storytelling is the communication between the storyteller and the audience (Diaz, Fields, 2007). Storytelling today is no longer a method limited solely to the field of social sciences and humanities. Stories are increasingly used in both business and marketing, areas where large amounts of data are managed. The story turns hard data into meaningful information that can be more easily conveyed to others, which also contributes to better decision making. In addition to giving seemingly impersonal data and charts the ability to capture audience attention, stories can be action-packed in many ways. This applies not only to the audience to whom the story is being told, but also to the authors of the story themselves. In their research, Halpern and Lepore (2015) attempted to evoke "authorial identity" in students to involve them more in their research work. They believe that storytelling is a more personal way of accessing scholarly work and that the desire to tell a personal story could encourage students to become more engaged in their work and less plagiarized. This should also contribute to a better quality of student work. The research showed that the students were extremely motivated and put a lot of effort into their work because they wanted to convey their story in the best possible way. They liked the freedom of creative expression that they did not normally feel when writing scientific papers. In doing so, Halpern and Lepore (2015) have proven that storytelling can also have a positive effect on the scientific field.

Storytelling has found its application in multimedia learning as well. Using multimedia - digital images, videos, voice recordings, and music - it is possible to create a digital story. The concept of digital storytelling originated in the 1990s when Dana Atchley, Joe Lambert, and Nina Mullen founded the Center for Digital Storytelling (CDS). Although the original application of digital stories was the telling of personal life stories, today they are increasingly used for educational purposes. On the one hand, they offer teachers the opportunity to attract students' attention and to bring rich multimedia content to students with complex material. Also, students who are given the task of making a digital story on a topic have the freedom to express themselves creatively, which fosters their interest in the task and in the detailed exploration of the topic they are addressing.

In his literature review The Role of Storytelling in Language Learning, Lucarevschi (2016) brings on storytelling:

Storytelling is one of the oldest forms of human communication, and much has been said in the literature about its effectiveness as a pedagogical tool in the development of language skills in first (L1) language, and also in a foreign or second language (L2), regardless of learners' age or background (e.g. Isbell, Sobol, Lindauer, Lowrance, 2004; Cameron, 2001). Furthermore, storytelling is even claimed to be more effective in language teaching than traditional teaching materials, such as textbooks. Indeed, studies generally believe that effectiveness of storytelling relies on the fact that it is fun, engaging and highly memorable, raising learners' interest in listening to stories, as well as in speaking, writing and reading about them (e.g. Atta-Alla, 2012, Kim, 2010; Wajnryb, 2003).

A story can get people's attention and evoke an emotional response, thus encouraging action to achieve a goal. Adding storytelling as a method of transferring knowledge to the benefits of multimedia learning is one way to achieve greater student motivation and interest in the material, and thus attract their attention to make learning effective and successful.

\section{An example of learning Japanese script thorough multimedia and storytelling}

The tutorial ${ }^{1}$ that is presented in this paper is a short version of a potentially larger more comprehensive tutorial completely based on a story and interactive play in a virtual environment. The presented version of the tutorial for learning Japanese Hiragana script covers fifteen of the existing forty-six Hiragana characters. The tutorial was created using the HTML graphic element Canvas. The goal of the tutorial presentation is to describe how this tutorial uses storytelling and multimedia to enhance learning and achieve language learning goals. The tutorial is originally intended for younger learners due to its playful nature, and it is appropriate for other audiences as well.

\footnotetext{
${ }^{1}$ The tutorial is created by Marija Bilić within the course Multimedia Knowledge Presentation and presented as a part of her BA thesis.
} 
The story that introduces the user to the tutorial is very simple, but it is designed to fit as many aspects as possible (learning Japanese script). Although not complex, it can be analyzed by Aristotle's threemember structure, which is also described in Nussbaumer Knaflic (2015). The introduction of the story clarifies the context. The learner gets to know the main character Milo who wanders around an unknown land (Figure 1). In this aspect, there is already a problem that will lead to conflict and tension. Milo meets an Asian-looking character who speaks to him in an unusual language. It is a moment of conflict. The protagonist faces a problem of misunderstanding, due to language (see Figure 2). Then Milu meets another character, a winged cat named Muki, who explains the situation to both the protagonist and the listener (Figure 3). The Asian-looking gentleman is the ruler of the strange land of Nihon and he alone has the power to get Milo out of that country so he can return home. However, in order for Milo to ask him for help, he must learn the language the ruler speaks. This part can be understood as an appeal for learning not only to the protagonist, but primarily to the user who identifies with the main character (Figure 4).

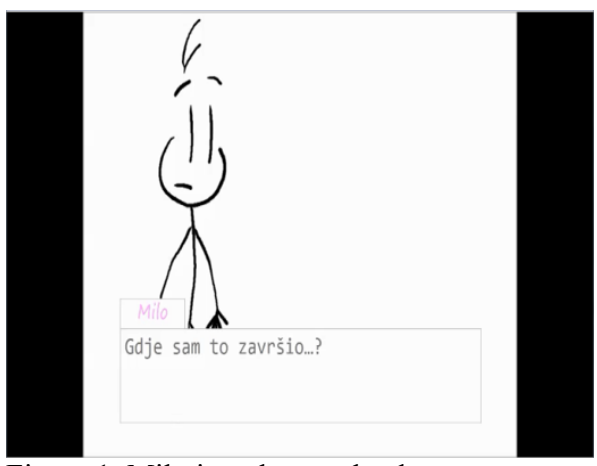

Figure 1. Milu in unknown land
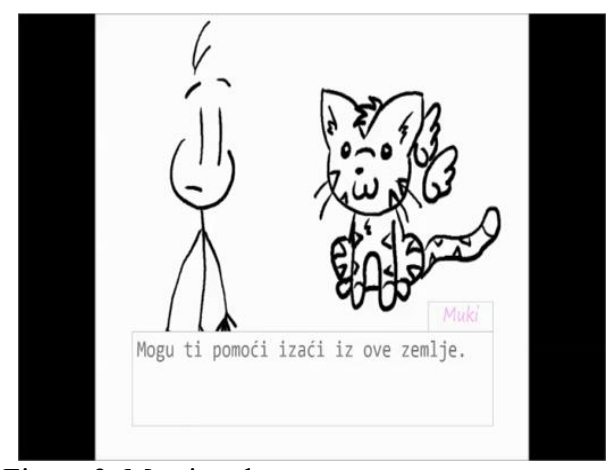

Figure 3. Meeting the cat
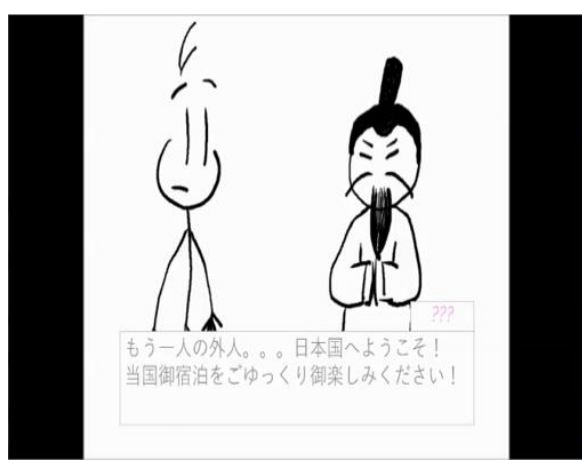

Figure 2. Conflict-unknown language
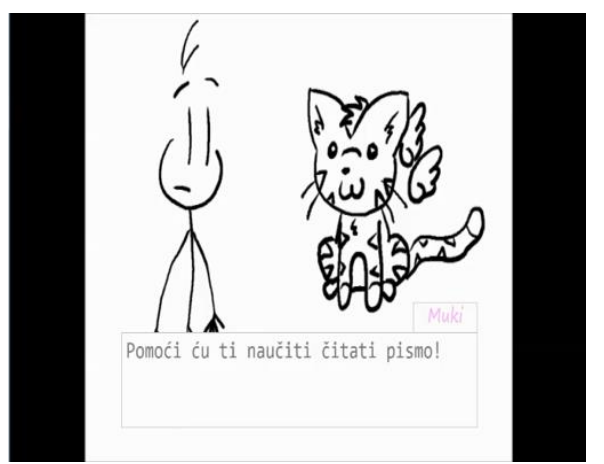

Figure 4. Getting help from the cat

The central part of the story is the main learning content itself (Figures 5-9). The student, together with the protagonist Milo, learns about the hiragana script and solves quizzes to test his knowledge. Each step in learning leads to culmination of the story, which culminates in a ruler's quiz. The ruler's quiz is the ultimate test of knowledge learned, and in the context of the story represents the protagonist's confrontation with a problem that led to conflict and tension. The story ends when the student/protagonist answers all the ruler's questions correctly. The protagonist then resolves the conflict and brings the story to an end. The learner needs to persevere until successful as this is the only way to continue the story.

In line with Arima (2009), the design was sought to include interface consistency, simplicity, ease of navigation, and an adequate combination of colors and fonts as shown in Figures 1-4 above, and Figures 5-9 below. Also, Segoe Print and Segoe Script fonts that resemble handwriting were used, with association to calligraphy. Considering multimedia, the tutorial uses text, image, sound, video and animation. A combination of text and image is dominant, which explains and illustrates the material. The main purpose of combination of text and image is to promote learning (Mayer 2017). Another purpose is to tell a story that increases the motivation to learn. Video as a combination of dynamic image and sound is used at the very beginning of the tutorial and serves to introduce the user to the story and explain its task (Figures 1-4). For this reason, the purpose of the video is obvious in 
the narrative aspect of the tutorials. Animations that represent only a dynamic image without a sound aspect are applied as feedback in quizzes (Figures 8 and 9). A certain atmosphere is reflected also through interactivity. When the learner answers the question correctly, an animation of a flowering Japanese cherry blossom is displayed. If the answer is incorrect, the flower turns black as if it faded.

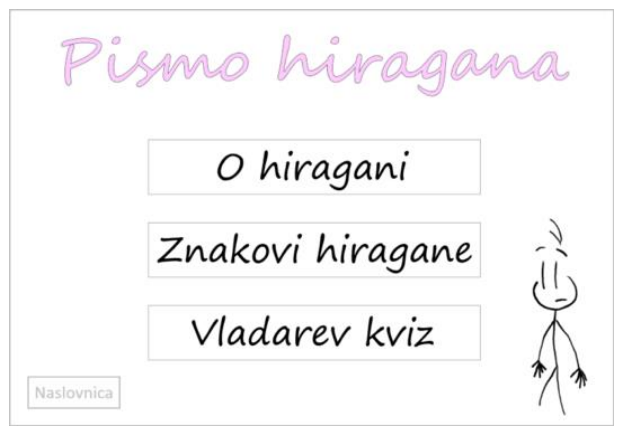

Figure 5. Initial tutorial screen

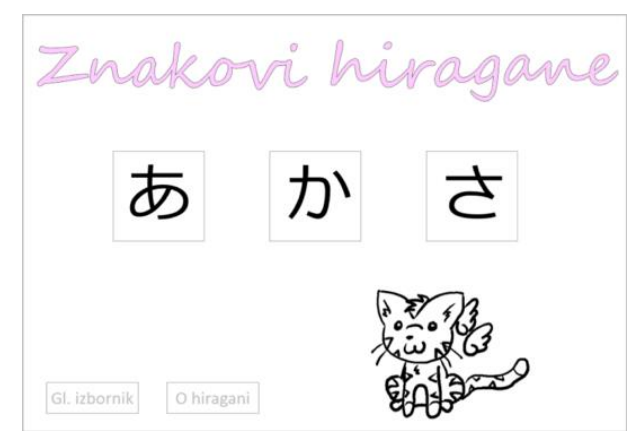

Figure 7. Hiragana Characters

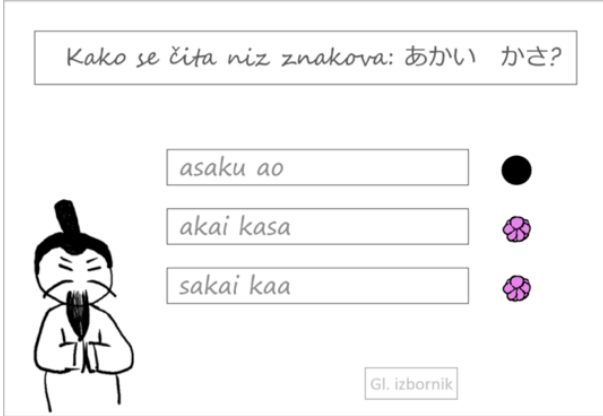

Figure 9. Pronouncing characters (quiz)

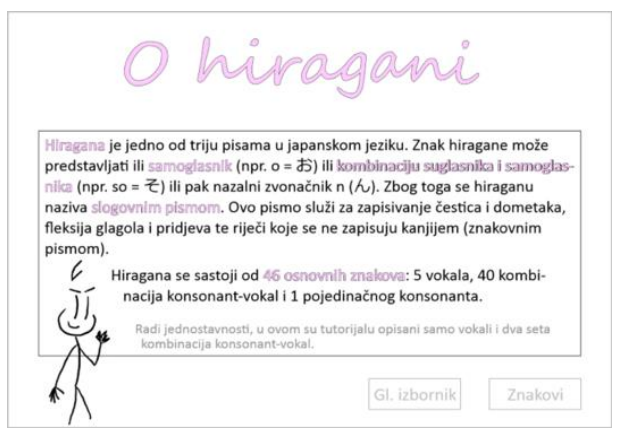

Figure 6. About Hiragana

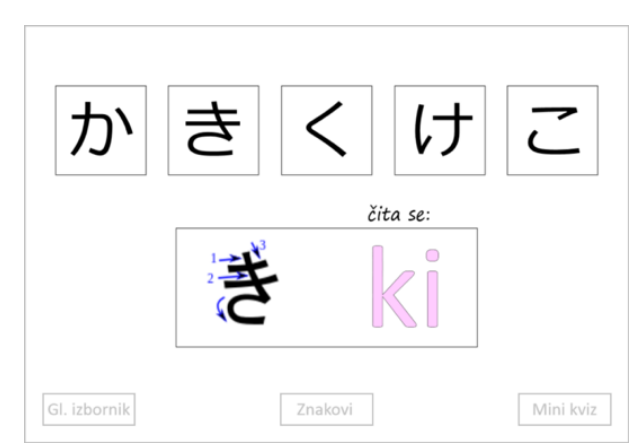

Figure 8. Reading and Writing Hiragana

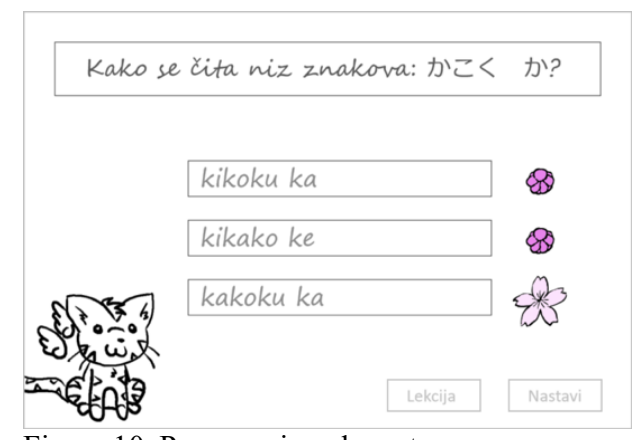

Figure 10. Pronouncing characters

Stepping in front of the ruler and answering his questions is a crucial moment of the story because depending on the student's, i.e. protagonist's performance, the story will have a positive ending. This fact serves as a motivation for the student to learn the material as much as possible and successfully solve the ruler's quiz. If the student fails to answer all the questions from the first, he or she must go a step back and repeat the preparatory quizzes. However, this is not failure for the learner, as there is an unlimited number of attempts for the learner to take on the ruler's quiz.

Milo happily leaves Nihon and goes home enriched with new knowledge and experiences. The very end of the story is no surprise as it was already announced in the introduction. For this reason, the end of the story may also be considered an incentive for the student to learn and repeat until the solution to the problem presented at the very beginning of the story is reached.

The story itself is simple and it is presented through a simple interface. The main goal is learning Japanese script, and due to the simplicity of the story, the learner is not distracted from the purpose of the tutorial. Nevertheless, the story itself and the multimedia elements that flow through the story, remove the sense of 'learning', and the students' motivation becomes organic. Furthermore, identifying with the main character instils empathy in the student and gives him a goal that, while seemingly different, actually leads to the learning goal, which is to master the hiragana letter. With storytelling 
techniques, the intention is to provide additional motivation for language learning and contribute to faster and better acquisition of new knowledge.

What is worth noting is the lack of animations to show proper character writing. These animations would greatly contribute to the learning of hiragana writing. They would clarify possible concerns that arise when writing character is shown solely by the image with accompanying arrows (Figure 7). Therefore, it would be advisable to introduce such animations in a future version of the tutorial. The same is true for listening and proper pronunciation exercises that would also contribute to better mastering characters. Recordings of the correct pronunciation could be implemented in conjunction with a textual representation of the reading of each character, which would result in the learner learning both visually and audibly. This could speed up the learning process and make learning faster. Pronunciation exercises could be performed so that the student repeats what he or she is hearing on the sound recordings. Both multimedia elements and storytelling, with varying degrees of realization, should contribute to better and faster learning.

\section{Conclusion}

Computer-assisted language learning (CALL) has nowadays emerged as a methodology of language learning that shows positive results concerning the speed and ease of language acquisition, standalone or combined with classical teaching. Along with CALL applications, there is often talk of multimedia. By using different types of media, multimedia environment can enable a better understanding of different aspects of a language. Images can create mnemonics for learning a letter or word, recordings of authentic pronunciation help practice listening and acquire the proper accent of language, and animations or videos can aid learning through interactivity, that mere text cannot. Multimedia offers a variety of opportunities to improve language learning and teaching, and there is a growing number of available multimedia applications and tutorials for language learning. Although the interest in learning Japanese has only recently emerged, a large number of existing multimedia applications and research on the subject point to the opportunities offered in the field of teaching the Japanese language. The complexity of the Japanese writing system raises many questions about how to speed up and improve the process of adopting letters. As outlined in this paper, a combination of storytelling and multimedia is promoted as a way to prompt interest for learning, maintain learning motivation and achieve learning goals.

\section{References}

Arima, Y. (2009). Importance of Aesthetics in Language Learning Websites: Students' Preferences Regarding Kana Learning Websites. Master thesis. University of Colorado

Beatty, K. (2003). Teaching and Researching Computer-assisted Language Learning. London [etc.]: Longman, 1-11, 16-51

Diaz, K., Fields, A. M. (2007). Digital Storytelling, Libraries, and Community. U: N. Courtney, ur., Library 2.0 and beyond: innovative technologies and tomorrow's user. $1^{\text {st }}$ ed. Westport: Libraries Unlimited, 129-139

Gilhooly, H. (2003). Beginner's Japanese Script. $2^{\text {nd }}$ ed. London: Hodder \& Stoughton, vii-x, 60-72

Halpern, R., Lepore, L. (2015). Scholarly Storytelling: Using Stories as a Roadmap to Authentic and Creative Library Research. / Swanson, T. A, Jagmann, H. (eds.). Not just where to click: teaching students how to think about information, $1^{\text {st }}$ ed. Chicago: Association of College and Reearch Libraries, A Division of the American Library Association, 349-365

Kišiček, S., Boras, D., Bago, P. (2010). Designing Educational Contents in and for the Electronic Environment. // ITI 2010 (32nd International Conference on Information Technology Interfaces); Proceedings of the ITI 2010 32nd International Conference on Information Technology Interfaces, Cavtat, 403-408

Lauc, T., Matić, S., Mikelić Preradović, N. (2007). Project of developing the multimedia software supporting teaching and learning of English vocabulary. // The Future of Information Sciences: INFuture2007 - Digital Information and Heritage. Zagreb, 493-499

Librenjak, S. (2018). Teaching Kana to Croatian Students through Native Language Mnemonics and Spaced Repetition. // Ueyama, M., Srdanović, I. (eds.) // Digital Resources for Learning Japanese. Bologna: Bononia University Press, 55-71

Lucarevschi, C. R. (2016). The Role of Storytelling on Language Learning: A Literature Review. // Working Papers of the Linguistics Circle of the University of Victoria 26, 1, 24-44

Matasić, I. and Dumić, S. (2012). Multimedia Technologies in Education. Media research: scientific and professional journal for journalism and media 18,1,143-151

Mayer, R. E. (2017) Using multimedia for e-learning. // Journal of Computer Assisted Learning 33, 5, October, 403-423

Moroz, A. (2013). App Assisted Language Learning: How Students Perceive Japanese Smartphone Apps. Master thesis. University of Alberta

Nussbaumer Knaflic, C. (2015). Storytelling with data: a data visualization guide for business professionals. Hoboken: John Wiley \& Sons, 2, 165-185 
M. Bilić, T. Lauc, S. Kišiček. Learning Japanese Script...

Seljan, S., Berger, N., Dovedan, Z. (2004). Computer-Assisted Language Learning (CALL). // MIPRO 2004; Proceedings of the 27th International Convention MIPRO 2004: MEET + HGS. Rijeka: Liniavera, 262-266

Yamaguchi, T. (2007). Japanese Linguistics. An Introduction. London, New York: Continuum 